Effects of additi on of hi nder ed phenol compounds to a segment ed pol yur et hane with shape menory on mechani cal yi el ding

\begin{tabular}{|l|l|}
\hline 著者 & $\begin{array}{l}\text { Kur i yagawa M zue, Kawamur a Takanobu, Hayashi } \\
\text { Shuni chi, N tta Koh- hei }\end{array}$ \\
\hline $\begin{array}{l}\text { j our nal or } \\
\text { publ i cat i on t i t l e }\end{array}$ & Journal of Nat er i al s Sci ence \\
\hline vol une & 46 \\
\hline number & 5 \\
\hline page r ange & 1264 1271 \\
\hline year & $2011-03-01$ \\
\hline URL & ht t p: //hdl . handl e. net /2297/25427 \\
\hline
\end{tabular}




\title{
Effects of Addition of Hindered Phenol Compounds to a Segmented Polyurethane with Shape Memory on Mechanical Yielding
}

\author{
Mizue Kuriyagawa ${ }^{1}$, Takanobu Kawamura ${ }^{1}$, Shunichi Hayashi ${ }^{2}$, Koh-hei Nitta $^{1 *}$ \\ ${ }^{1}$ Division of Material Sciences, Graduate School of Natural Science and Technology, Kanazawa \\ University, Kakuma Campus, Kanazawa, Ishikawa, 920-1192 Japan \\ ${ }^{2}$ SMP Technologies Inc., Sendagaya, Shibuya-ku, Tokyo, 151-0051 Japan
}

*Corresponding author, Koh-hei Nitta (Tel:+81-76-234-4818, FAX:+81-76-264-6220 E-mail: nitta@t.kanazawa-u.ac.jp)

\begin{abstract}
The mechanical yielding behavior of the shape memory polyurethane (SMP) and its composite samples were investigated to verify the effect of addition of hindered phenol. The composite samples were prepared using SMP as matrix and hindered phenol (AO-80) as filler, and then tensile tests were carried out at a range of temperatures and with different fixed crosshead speeds. According to the tensile data at $25^{\circ} \mathrm{C}$, the yield stress was increased by adding AO-80. In terms of the Eyring theory, the activation volume of deformation units decreased with increase of the amount of AO-80 added. This is because the packing of the hard segments is enhanced by addition of AO-80. Consequently, it was suggested that the yield process is caused by the rotation of hard segment domains within the deformed plastic domains composed of glassy soft segments.
\end{abstract}

Keyword: shape memory polyurethane, composite, yield behavior, Eyring rate process 


\section{Introduction}

Segmented polyurethane is a multi-block polymer consisting of hard segments and soft segments. The hard segments are made up of extended isocyanates associated in domains because of rigidity and hydrogen bonding, and act as thermally reversible crosslinks between soft segments of the matrix. Most segmented polyurethanes of which the soft segments have glass transition temperature $T_{\mathrm{g}}$ near room temperature have shape memory properties, which are shape fixing and shape recovery. Thus the elastic response of the soft segment phase is associated with shape memory effect, and the shape memory polyurethane (SMP) is in the glassy state in room temperature.

In general, reinforcement of polymer is achieved in composites by adding organic or inorganic fillers to the polymer matrix. Much research has been conducted on reinforcement of the mechanical properties of matrix polymers by adding fillers [1-4]. Tortora et al. [5] reported that incorporation of organically modified montmorillonites in polyurethane gave an improvement in the elastic modulus and yield stress: on the other hand, the stress and strain at break decreased with increase of the amount of clay added. Finnigan et al. [6] found that the loading organically-modified layered silicate leads to an increase in $T_{\mathrm{g}}$ of soft segments and to a high Young's modulus, but lowered the yield stress and the strain at break.

Our previous work [7] showed that the stress-strain behavior of SMP plastics differs from that of typical polyurethane elastomers. The stress-strain curves of the SMP showed a clear yield peak similar 
to that of common ductile plastic materials at room temperature, because the soft segment phase is in the glassy state at room temperature. In addition, it was found that the mechanical properties of the SMP are improved by adding hindered phenol compounds and nano-size silica particles. Adding the hindered phenol compounds enhanced the yield stress because the hindered phenols were completely dissolved around the hard segment domains, leading to packing of hard segments and enhancing the cohesive force between hard segments. Conversely, the incorporation of silica particles into the SMP had little effect on the yield stress but increased Young's modulus. It was suggested that the bulkiness of the silica particles gives resistance to Poisson construction under tensile deformation, resulting in an increase in Young's modulus.

Considering the yielding mechanism of glassy polymers, the Eyring rate theory [8-13] has been used as a theoretical basis for plastic deformation. According to the Eyring theory, the yielding process is assumed to be caused by stress-activated jumps of molecular segments, and the mechanical yield flow is characterized by the activation volume of deformation units and the activation energy for the flow process. Cook et al. [12] reported that the activation volume of epoxy resin is relatively insensitive to changes in crosslink density or composition, but increased as the temperature is raised. Furthermore, Nofal et al. [13] showed that for PAN-based carbon fiber/polycarbonate composites, addition of the filler reduced $T_{\mathrm{g}}$ of the composites, and the activation volume and activation energy are appreciably increased with increasing filler concentration. 
In our previous work, it was found that the addition of AO- 80 strongly enhances the yield stress,

because the cohesion of hard segment domains was increased due to the packing of hard segments induced by adding AO-80. The present work gives a physical insight, using an Eyring rate process, into the effect of addition of hindered phenol compounds to SMP on the yield process. In addition, we present a deformation model for large-scale transformation of SMP under tensile yield deformation. 


\section{Material}

A polyurethane based shape memory polymer (DIARY, MM4450: DiAPLEX Co., Ltd) with weight average molecular weight $\left(M_{\mathrm{w}}\right)$ and molecular weight distribution $\left(M_{\mathrm{w}} / M_{\mathrm{n}}\right) 200 \times 10^{3} \mathrm{~g} \mathrm{~mol}^{-1}$ and 2.4, respectively, was as the matrix polymer. The hindered phenol compound 3,9-bis[1,1-dimethyl-2 \{ $\beta$-(3-tertbutyl-4-hydroxy-5-methylphenyl)propionyloxy $\}$-ethyl]-2,4,8,10-tetraoxa spiro[5,5]-undecane (AO-80) was used as filler for enhancement of the mechanical properties of SMP. AO-80 is a commercial antioxidant (ADK STAB AO-80; Asahi Denka Industries Co.). The glass transition temperature and melting temperature of AO-80 were 40 and $121^{\circ} \mathrm{C}$, respectively [14].

\section{Sample Preparation}

SMP pellets were kneaded by mixing rollers at $185^{\circ} \mathrm{C}$ for 3 min and a fixed amount of $\mathrm{AO}-80$ powder from 0 to $10 \mathrm{wt} \%$ was subsequently added to the kneaded SMP, then the mixture was kneaded at $185^{\circ} \mathrm{C}$ for $7 \mathrm{~min}$.

The kneaded composite samples were compression-molded at $180^{\circ} \mathrm{C}$ for $5 \mathrm{~min}$, then pressed at $180^{\circ} \mathrm{C}$ under a pressure of $200 \mathrm{~kg} \cdot \mathrm{cm}^{-2}$ for 5 min using a laboratory hot press. The composites were then cooled slowly at room temperature $\left(25^{\circ} \mathrm{C}\right)$ to prepare sample sheets with thickness about $200 \mu \mathrm{m}$ for the measurements. The characteristics of the samples are given in Table 1. 


\section{Experimental}

\section{Dynamic Mechanical Analysis}

Dynamic viscoelastic spectra were determined using a DVE-V4 (Rheology Co.) instrument.

The activation energy for the glass transition relaxation process was evaluated from the frequency dependence of the dynamic mechanical spectra around the glass transition temperature $T_{\mathrm{g}}$. Rectangular specimens with length $20 \mathrm{~mm}$, width $5 \mathrm{~mm}$ and thickness about $200 \mu \mathrm{m}$ were used for dynamic viscoelastic measurements. The measurements were carried out at constant frequencies in the range 1-200 $\mathrm{Hz}$ with fixed amplitude of $2 \mu \mathrm{m}$. The tensile storage modulus $E^{\prime}$, loss modulus $E^{\prime \prime}$, and loss tangent $\tan \delta$ were recorded from $0^{\circ} \mathrm{C}$ to $70^{\circ} \mathrm{C}$ at heating rate $2^{\circ} \mathrm{C} \min ^{-1}$ under a nitrogen atmosphere.

\section{Tensile tests}

Uniaxial tensile behavior was investigated using a tensile instrument (INSTRON model 4466)

with dumbbell shape specimens with gauge length $10 \mathrm{~mm}$, ligament length $4 \mathrm{~mm}$ and overall length 30 $\mathrm{mm}$. The specimens were punched out from the compression molded sheets. Strain-stress curves were obtained at 25,32 and $45^{\circ} \mathrm{C}$ and humidity $<50 \%$, at constant cross-head speeds in the range $1-100 \mathrm{~mm}$ $\min ^{-1}$. The tensile strain was calculated from the ratio of the increment of the length between the clamps to the initial gauge length. The tensile stress was determined by dividing the tensile load by the initial cross sectional area. 


\section{Results and Discussion}

The elastic storage modulus $E^{\prime}$, loss modulus $E^{\prime \prime}$ and loss tangent $\tan \delta$ of all samples obtained from dynamic viscoelastic measurements are shown in Figure 1. Each sample showed a well defined glass relaxation at about $45^{\circ} \mathrm{C}$; the values of $E^{\prime}$ started to decrease, and the maxima in the $E^{\prime \prime}$ curves appeared at around that temperature. The values of $T_{\mathrm{g}}$ estimated from the maxima in the $E^{\prime \prime}$ curves measured at constant frequency of $10 \mathrm{~Hz}$ are summarized in Table 1. These glass relaxations are ascribed to release of micro-Brownian motions of soft segments. The $T_{\mathrm{g}}$ value was independent of the proportion of AO-80, implying that AO- 80 has no ability to interact with the soft segments. In addition, for the purpose of quantitatively characterizing the molecular mobility of soft segments, the apparent activation energy for micro-Brownian motion of soft segments was determined from the frequency dependence of $T_{\mathrm{g}}$ on the assumption that the glass transition relaxation progresses in accordance with the Arrhenius equation (Figure 2).

$$
v=v_{0} \exp \left(-\frac{\Delta H_{T g}}{R T_{g}}\right)
$$

where $v$ is the frequency factor, $v_{0}$ is the pre-exponential factor and $R$ is the gas constant. The experimental values of the energy barrier $\Delta H_{T g}$ estimated by using Eq.(1) are listed in Table 1. The activation energies of all samples were almost the same, independent of the AO-80 content; it follows that the addition of AO-80 had no effect on the mobility of soft segments but affected the hard segments.

The stress-strain curves of pure SMP and SMP/AO-80(90/10) measured at 25,32 , and $45^{\circ} \mathrm{C}$ 
and constant crosshead speed of $10 \mathrm{~mm} \mathrm{~min}^{-1}$ are shown in Figure 3. The sharp yield peak that is typical of plastic materials was observed in the stress-strain curves of all samples at $25^{\circ} \mathrm{C}$, and the stress-strain curves in the post-yield region showed a neck propagation region (Figure 3(a)). The yield peak became broader at $32^{\circ} \mathrm{C}$ and disappeared at $45^{\circ} \mathrm{C}$. After the neck expanded to the whole of the specimen, a strain hardening region appeared where the stress steeply increased again, then the specimen fractured, as shown in Figure 3(b). The yield stress values estimated from the maximum in the stress-strain curves in the strain region of Figure 3(a) are plotted against the AO-80 content in Figure 4. The yield stress values measured at $25^{\circ} \mathrm{C}$ were found to increase with the proportion of AO- 80 while the values at 32 and $45^{\circ} \mathrm{C}$ were less sensitive to the AO- 80 content. This is because the glass relaxation of AO- 80 occurs at $40^{\circ} \mathrm{C}$. The thermal activation of molecular mobility due to the glass relaxation of AO- 80 overcomes the interaction between the hard segments and AO-80, with the result that the addition of AO-80 had little effect on the yield stress values of SMP measured at 32 and $45^{\circ} \mathrm{C}$.

The strain rate and temperature dependences of the yield behavior of glassy polymers have been commonly found to conform to the model for thermally activated rate processes proposed by Eyring [15].

The fundamental flow process is the jump of a deformation unit from its original position to a more stable state under the action of a shear stress. We assume that this flow process takes place at the yield point of the tensile deformation, and that there is no contribution from the hydrostatic stress. In the 
case of sufficiently large yield stress levels, we have

$$
\dot{\varepsilon}=\dot{\varepsilon}_{0} \exp \left(-\frac{\Delta H}{R T}\right) \exp \left(\frac{\sigma_{y} V^{*}}{2 R T}\right)=\varepsilon_{0} \exp \left(-\frac{\Delta H-\sigma_{y} V^{*} / 2}{R T}\right)
$$

where $\dot{\varepsilon}$ is strain rate, $\dot{\varepsilon}_{0}$ is an arbitrary constant, $\Delta H$ is the activation energy, $\sigma_{\mathrm{y}}$ is the yield stress, and $V^{*}$ is the activation volume. Using Eq. (2), we can estimate the activation volume from the results of tensile tests performed with different crosshead speeds or strain rates at a fixed temperature. In addition, the activation energy can be obtained from tensile test data obtained at different crosshead speeds and different temperatures.

As shown in Figure 5, the plot of yield stress $\sigma_{y}$ versus $\ln \dot{\varepsilon}$ at different temperatures gives a set of straight lines which fit Eq. (2) well. The plots at 32 and $45^{\circ} \mathrm{C}$ gives parallel lines, the slope of which is large than that of the line at $25^{\circ} \mathrm{C}$, indicating that the yield flow mechanism at $25^{\circ} \mathrm{C}$ is different from that at 32 and $45^{\circ} \mathrm{C}$. This behavior was also seen for other SMP/AO- 80 samples. The slope of the lines gives the activation volume of the deformation unit. Figure 6 shows that the activation volume decreased linearly with AO- 80 content at $25^{\circ} \mathrm{C}$. This suggests that the addition of AO- 80 increased the resistance to flow of the deformation units in the yield region. By contrast, the activation volumes at 32 and $45^{\circ} \mathrm{C}$ had almost the same value, and were independent of the AO- 80 content. This is because the glass transition relaxation of $\mathrm{AO}-80$ is around $40^{\circ} \mathrm{C}$ and the $\mathrm{AO}-80$ molecules are released from the hard segment domains.

The activation energies of all samples (given in Table 2) were almost constant, indicating that 
the energy required for flow of the deformation units without tension was independent of AO-80 content.

It is interesting to note that the values of the activation energy were almost in accordance with the activation energy calculated from the dynamic mechanical data. This implies that the yielding process is closely related to the mechanical activation of soft segments.

Cooper et al. [16,17] studied the orientation behavior of polyurethane block copolymers, and showed that negative orientation of hard segments was obtained at low strains, and at the higher strains the orientation direction became the direction of stretching. In addition, according to the in-situ SAXS study by Blundell et al. [18], hard phase domains behaving as particles are affinely deformed under a tensile deformation. Considering that the hard segment domains were formed by hydrogen bonding between urethane groups of hard segments, the growth of the length $L$ in the direction of the chain axis is restricted by the alternating hard and soft segments and the hard segment domains grow only in the stacking direction [16]. It follows that the ratio $L / D$ between the length $L$ and thickness $D$ of the hard domains is extremely small. Here we extend the micro-morphology model for elastic SMP to that of plastic SMP where the hard segment domains are assumed to be encapsulated by a glassy soft segment phase.

On the basis of the present experimental results, we present a deformation model for the present SMP plastics in Figure 7(a). The domain in which the hard segment domains are surrounded by glassy soft segments below $T_{\mathrm{g}}$ is termed the "plastic domain", and this plastic domain acts as the 
deformation unit in the yielding process. In the initial tensile deformation (Figure 7(b)), the plastic domains undergo affine deformation in the tensile direction, i.e. the plastic domain is affinely compressed perpendicular to the tensile direction by Poisson construction. Accordingly, Young's modulus is determined by the resistance to construction of the plastic domains. As the specimen is subsequently extended beyond the initial strain region, the affine deformation of the plastic domains exerts a direct construction force on the stacked hard segment domains. When the mechanical energy stored in the deformed plastic domains exceeds a threshold level, the hard segment domain starts to rotate to the stretching direction (Figure 7(c)), with the results in that the hard segment orients to the direction perpendicular to the extension, as demonstrated by Cooper et al [16]. Furthermore, according to Yeh et al. [19], the hard segment lamellae and stacks are both tilted paralleled to the draw direction, and then the hard domains rotate to the stretching direction with the hard segments perpendicular to the draw axis. Consequently, the torque exerting hard segment domains are likely to be directly related to the yield stress, and the mechanical energy required for the rotation corresponds to the "yield energy". After rotation of the hard domains the stored energy is released, leading to a yield drop in the stress-strain curve.

Our previous study [7] showed an upward (higher wavenumber) shift of a hydrogen-bonded $\mathrm{C}=\mathrm{O}$ stretching band at around $1710 \mathrm{~cm}^{-1}$ due to the addition of AO- 80 . Hence the addition of AO- 80 compresses the hard segment domains as illustrated in Figure 8. The deformation model of SMP and SMP/AO-80 in the yield region is schematically illustrated in Figure 9, where the arrow in the hard 
segment domain denotes the stacking direction of the hard segments. Bearing in mind that the thickness of the hard segment domains is reduced by the addition of AO- 80 and the size of the plastic domain is independent of the addition of AO-80, a higher strain is necessary to rotate the hard segment domains for SMP/AO-80 as compared with SMP. Consequently, the force required for rotating the hard segment domains of SMP/AO-80 becomes higher than for SMP, resulting in the yield stress increasing with addition of AO-80. In the model, the thickness of the stacked hard segment domains acts as the effort distance $l$, and the torque required for rotating the domains is given by $N=F \times l$ where $F$ is the moment from external loads.

In view of the fact that the yield of SMP follows the activated mechanism of soft segments, the yield can be considered to be caused by the plastic flow of soft segments around the hard segment domains, brought about by the rotation of stacked hard segment domains to the stretching direction. It is likely, therefore, that the activation volume $V^{*}$ obtained from the application of Eyring's theory to the yielding behavior corresponds to the flow volume of the soft segments within plastic domains (see Figure 9). Furthermore, the fact that the activation volume at $25^{\circ} \mathrm{C}$ decreases with increasing amount of $\mathrm{AO}-80$ added as shown by Figure 6, is consistent with the reduction of the volume of the flowing soft segments brought about by the compression of the hard segment domains due to the addition of AO-80. We found a linear relationship, shown in Figure 10, between the activation volume and the positive shift of $\mathrm{C}=\mathrm{O}$ bands in FTIR spectra, reflecting the aggregation of hard segments. This suggests that the thickness of 
hard segment domains is decreased by adding AO-80. The details of the FTIR measurements can be found in our previous work [7]. According to Figure 10, an empirical relation is obtained as follows:

$$
\Delta v=\alpha\left(V_{0}^{*}-V^{*}\right)
$$

where $\alpha$ is the proportionality constant $\left(2.35 \times 10^{3} \mathrm{~mol} /\left(\mathrm{cm} \mathrm{m}^{3}\right)\right)$, and $V_{0}{ }^{*}$ and $V^{*}$ are the activation volumes of pure SMP and SMP/AO- 80 respectively $\left(V_{0}^{*}\right.$ was estimated from the intercept of the activation volume in Figure 6.). This is likely because the frequency shift $\Delta v$ reflects the packing of hard segment domains from addition of AO-80. The torque $N$ acting on the hard segment domains in the yield process can be considered to be the activated mechanical energy in the Eyring process:

$$
N=|F \times l|=\sigma_{y} V^{*}
$$

Assuming that the threshold level for the yielding process is the excited mechanical energy in Eyring's rate theory, the value of $\sigma_{y} V^{*}$ corresponds to the "yield energy". Then Eq.(3) can be rewritten as

$$
\Delta v=\alpha V^{*}\left(1-\frac{\sigma_{y 0}}{\sigma_{y}}\right)
$$

where $\sigma_{y 0}$ is the yield stress of SMP and $\sigma_{y}$ is the yield stress of SMP/AO-80. Our theoretical considerations lead us to the result that the peak shift $\Delta v$ is proportional to $\left(1-\sigma_{\mathrm{y} 0} / \sigma_{\mathrm{y}}\right)$. As shown in Figure 11 the experimental values almost fall on the theoretical lines calculated from Eq. (5). Thus the addition of AO- 80 reduces the activation volume, leading to increase of the yield stress $\sigma_{y}$ required for plastic flow. After the yielding process, the plastic domains will be fragmented so that the external load is directly exerted on the hard segment domains surrounded by soft segments, and the hard segment 
domains will orient to the stretching direction in the post-yield region as suggested by Cooper et al [16].

Here we consider the relationship between the thermal activation process of Arrhenius type (Eq.(1)) and the mechanical activation process estimated from the Eyring's rate theory. According to Eyring's theory, the energy barrier can be considered suppressed by the mechanical work $\sigma V^{*} / 2$ when the stress $\sigma$ was applied to the system. The rate for mechanical flow of the deformation units can be formulated by Eq.(2), where this flowing stress corresponds to the yield stress $\sigma_{\mathrm{y}}$.

Actually, the values of each kinetic parameters for glass relaxation and mechanical yielding processes calculated from the experimental data in Tables 1 and 2 were found to be almost the same with each other (Table 3).

$$
\frac{\Delta H_{T g}}{R T_{g}}=\frac{\Delta H-\sigma_{y} V^{*} / 2}{R T}
$$

The experimental fact that $\Delta H_{T \mathrm{~g}}$ and $\Delta H$ is in good agreement as well as Eq.(6) is held indicates that the mechanical yielding is caused by supplying the mechanical work $\sigma V^{*} / 2$ to the thermal energy due to temperature reduction from $T_{\mathrm{g}}$. This quantitative agreement in Table 3 also strongly suggests that the yield process is caused by the movement of hard segments within the plastic domains composed of glassy soft segments. 


\section{Conclusions}

Composite samples were prepared using SMP as a matrix and hindered phenol (AO-80) as filler with proportion $0-10 \mathrm{wt} \%$. The dynamic viscoelastic measurements showed that the values of $T_{\mathrm{g}}$ and the activation energy corresponding to the glass relaxation of soft segments are almost constant despite the addition of AO-80. The results let us to conclude that AO-80 interacts not with soft segments but with hard segments. In addition, the tensile tests at different temperatures showed that the yield stress is increased by adding $\mathrm{AO}-80$ at $25^{\circ} \mathrm{C}$, however the yield stress is independent of the addition of $\mathrm{AO}-80$ at higher temperatures because the glass relaxation of AO- 80 occurs at about $40^{\circ} \mathrm{C}$. According to Eyring's rate theory, the activation volume of the deformation unit decreased linearly with increasing AO- 80 content at $25^{\circ} \mathrm{C}$, indicating that the addition of $\mathrm{AO}-80$ inhibits the flow of deformation units. In addition, the activation energies for all samples were almost the same and correspond to the activation energy for mechanical relaxation of soft segments. This means that the addition of AO- 80 has no effect on the energy required for flow of the units without tension, and the yielding process is related to the activation mechanism of soft segments. Considering these results and previous work [12,13], we suggest that the yield process is caused by the rotation of hard segment domains within the plastic domains composed of glassy soft segments encapsulating hard domains. 
Acknowledgment: The authors are grateful for the financial support for this work from SMP Technologies

Inc. 


\section{References}

[1] Cho J W. Kim J W. Jung Y C. GooN S (2005) Macromol Rapid Commun 26: 412-416

[2] Nunes R C R. Pereira R A. Fonseca J L C. Pereira M R (2001) Polym Test 20: 707-712

[3] Ohki T. Ni Q-Q. Ohsako N. Iwamoto M (2004) Compos Part A 35: 1065-1073

[4] Gunes I S. Cao F. Jana S C (2008) Polymer 49: 2223-2234

[5] Tortora M. Gorrasi G. Vittoria V. Galli G. Ritrovati S. Chiellini E (2002) Polymer 43: 6147-6157

[6] Finnigan B. Martin D. Halley P. Truss R. Campbell K (2004) Polymer 45: 2249-2260

[7] Kuriyagawa M. Kawamura T. Hayashi S. Nitta K-H (2010) J Appl Polym Sci: 117:1695

[8] Eyring H (1936) J Chem Phys 4: 283-291

[9] Glasstone S. Laidler K J. Eyring H.(1941) The Theory of Rate Processes. McGraw-Hill, New York.

London

[10] Halsey G H. White H J. Eyring H (1945) Tex Res J 15: 295-311

[11] Reichardt C H. Eyring H (1946) Tex Res J 16: 635-642

[12] Cook W C. Mayr A E. Edward G H (1998) Polymer 39: 3725-3733

[13] Nofal M M. Zihlif A M. Ragosta G. Martuscelli E (1996) Polymer Composites 17: 705-709

[14] Wu C. Yamagishi T-A. Nakamoto Y. Ishida S-I. Nitta K-H (2000) J Polym Sci Part B Polym Phys 38: $2943-2953$

[15] Ward I M. Sweeney J (2004) The Mechanical Properties of Solid Polymers second edition,Wiley, 
New York

[16] Seymour R W. Allegrezza A E Jr. Cooper S L (1973) Macromolecules 6: 896-902

[17] Allegrezza A E Jr. Seymour R W. Ng H N. Cooper S L (1974) Polymer 15: 433-440

[18] Blundell D J. Eeckhaut G. Fuller W. Mahendrasingam A. Martin C (2002) Polymer 43: 5197-5207

[19] Yeh F. Hsiao B. S. Sauer B. B. Michel S. Siesler H. W. (2003) Macromolecules 36: 1940-1954 


\section{Figure Captions}

Fig.1 Dynamic mechanical spectra of SMP and SMP/AO-80 samples measured at constant frequency of $10 \mathrm{~Hz}$.

Fig.2 Arrhenius plots of dynamic mechanical data in the glass relaxation region of soft segments.

Fig.3 Stress-strain curves (a) in the yield region and (b) over the whole strain region of SMP and $\mathrm{SMP} / \mathrm{AO}-80(90 / 10)$; measured at $10 \mathrm{~mm} \mathrm{~min}^{-1}$ and at 25,32 , and $45^{\circ} \mathrm{C}$.

Fig.4 Yield stress normalized by that of pure SMP, as a function of AO-80 content at 25,32 , and $45^{\circ} \mathrm{C}$.

Fig.5 Strain rate dependence of yield stress of pure SMP at different temperatures.

Fig.6 AO-80 content dependence of the activation volume at different temperatures estimated from Eyring's theory.

Fig.7 Yield deformation model of SMP below $T_{\mathrm{g}}$ of the soft segments. 
Fig.8 Schematic illustrations of the effect of AO-80 addition on the aggregation state of hard segments:

(a) pure SMP, and (b) SMP/AO-80.

Fig.9 Deformation model for yielding process of pure SMP and SMP/AO-80.

Fig.10 FTIR peak shift of the hydrogen-bonded $\mathrm{C}=\mathrm{O}$ band $\left(1710 \mathrm{~cm}^{-1}\right)$ induced by the addition of AO- 80 , versus the activation volume from Eyring's theory.

Fig.11 The dependence of $\left(1-\sigma_{\mathrm{y} 0} / \sigma_{\mathrm{y}}\right)$ on the peak shift of the hydrogen-bonded $\mathrm{C}=\mathrm{O}$ band, where $\sigma_{\mathrm{y} 0}$ and $\sigma_{\mathrm{y}}$ are the yield stresses of SMP and SMP/AO-80, respectively.

Table 1 Characteristics of glass transition of soft segments.

Table 2 Results of Eyring analysis for mechanical yielding activation volume and activation energy.

Table 3 Kinetic parameters for glass transition and mechanical yield processes. 
Table 1

\begin{tabular}{lcc}
\hline Sample & $T_{\mathrm{g}} /{ }^{\circ} \mathrm{C}$ & $\Delta H_{T \mathrm{~g}} / \mathrm{kJ} \mathrm{mol}^{-1}$ \\
\hline SMP & 48 & 530 \\
SMP/AO-80(99/1) & 48 & 530 \\
SMP/AO-80(97/3) & 48 & 530 \\
SMP/AO-80(95/5) & 47 & 510 \\
SMP/AO-80(92/8) & 47 & 510 \\
SMP/AO-80(90/10) & 48 & 510 \\
\hline
\end{tabular}

$T_{\mathrm{g}}$ : glass relaxation temperature; $\Delta H_{\mathrm{Tg}}$ : activation energy for glass relaxation 
Table 2

\begin{tabular}{|c|c|c|c|c|}
\hline \multirow[t]{2}{*}{ Sample } & \multicolumn{3}{|c|}{$V^{*} / 10^{-3} \mathrm{~m}^{3} \mathrm{~mol}^{-1}$} & \multirow[t]{2}{*}{$\Delta H / \mathrm{kJ} \mathrm{mol}^{-1}$} \\
\hline & $25^{\circ} \mathrm{C}$ & $32^{\circ} \mathrm{C}$ & $45^{\circ} \mathrm{C}$ & \\
\hline SMP & 1.61 & 0.847 & 0.981 & 520 \\
\hline SMP/AO-80(99/1) & 1.40 & 0.859 & 0.908 & 520 \\
\hline SMP/AO-80(97/3) & 1.36 & 0.987 & 0.970 & 520 \\
\hline SMP/AO-80(95/5) & 1.20 & 1.02 & 1.01 & 530 \\
\hline SMP/AO-80(92/8) & 1.13 & 1.01 & 1.02 & 460 \\
\hline SMP/AO-80(90/10) & 1.08 & 1.08 & 1.03 & 460 \\
\hline
\end{tabular}


Table 3

\begin{tabular}{ccc}
\hline AO-80 content/wt $\%$ & $\frac{\Delta H_{T g}}{R T_{g}}$ & $\frac{\Delta H-\sigma_{y} V^{*} / 2}{R T}$ \\
\hline 0 & 184 & 180 \\
3 & 184 & 186 \\
5 & 184 & 183 \\
8 & 178 & 166 \\
10 & 178 & 167 \\
\hline
\end{tabular}




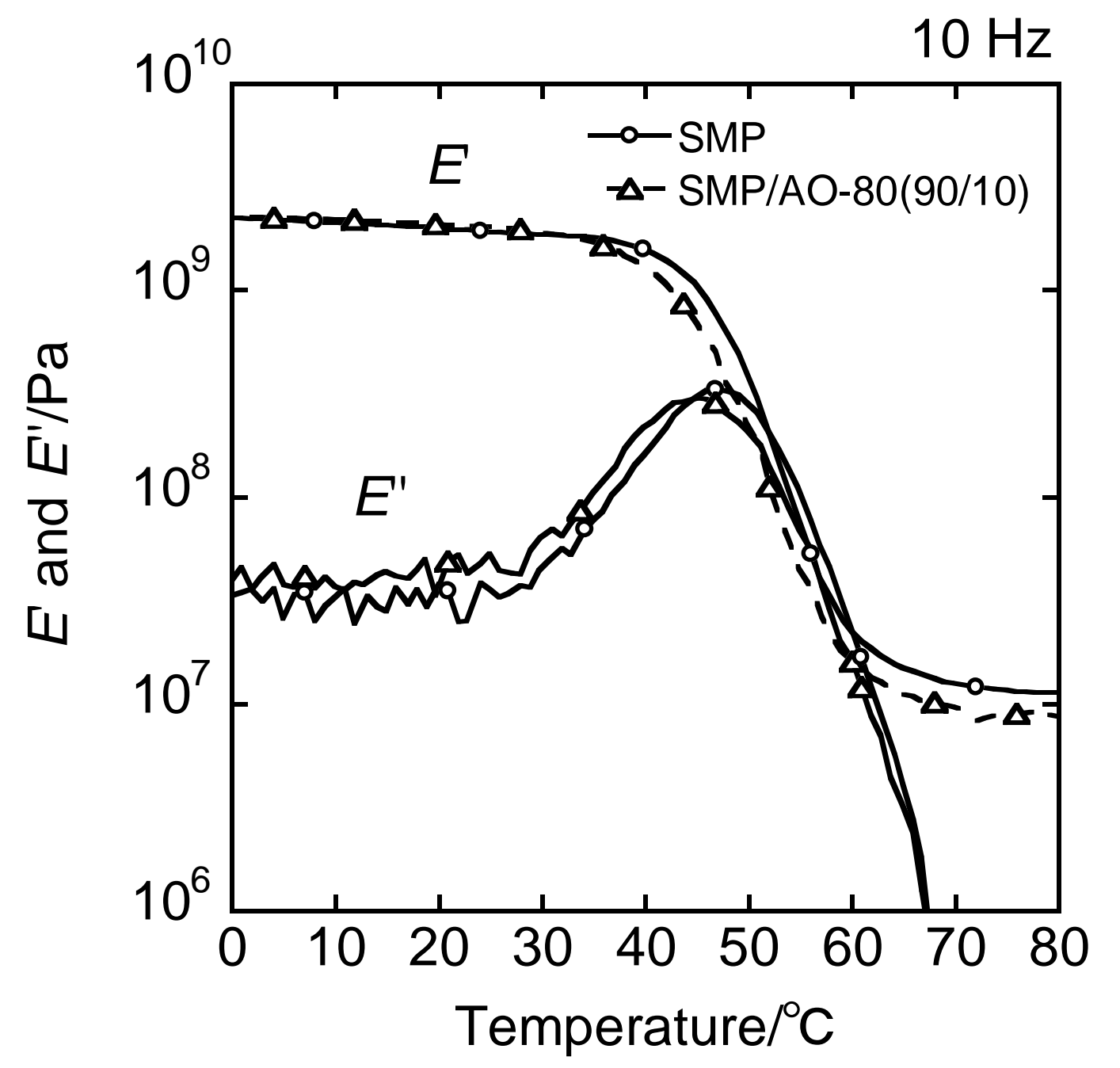

Figure 1 Kuriyagawa 


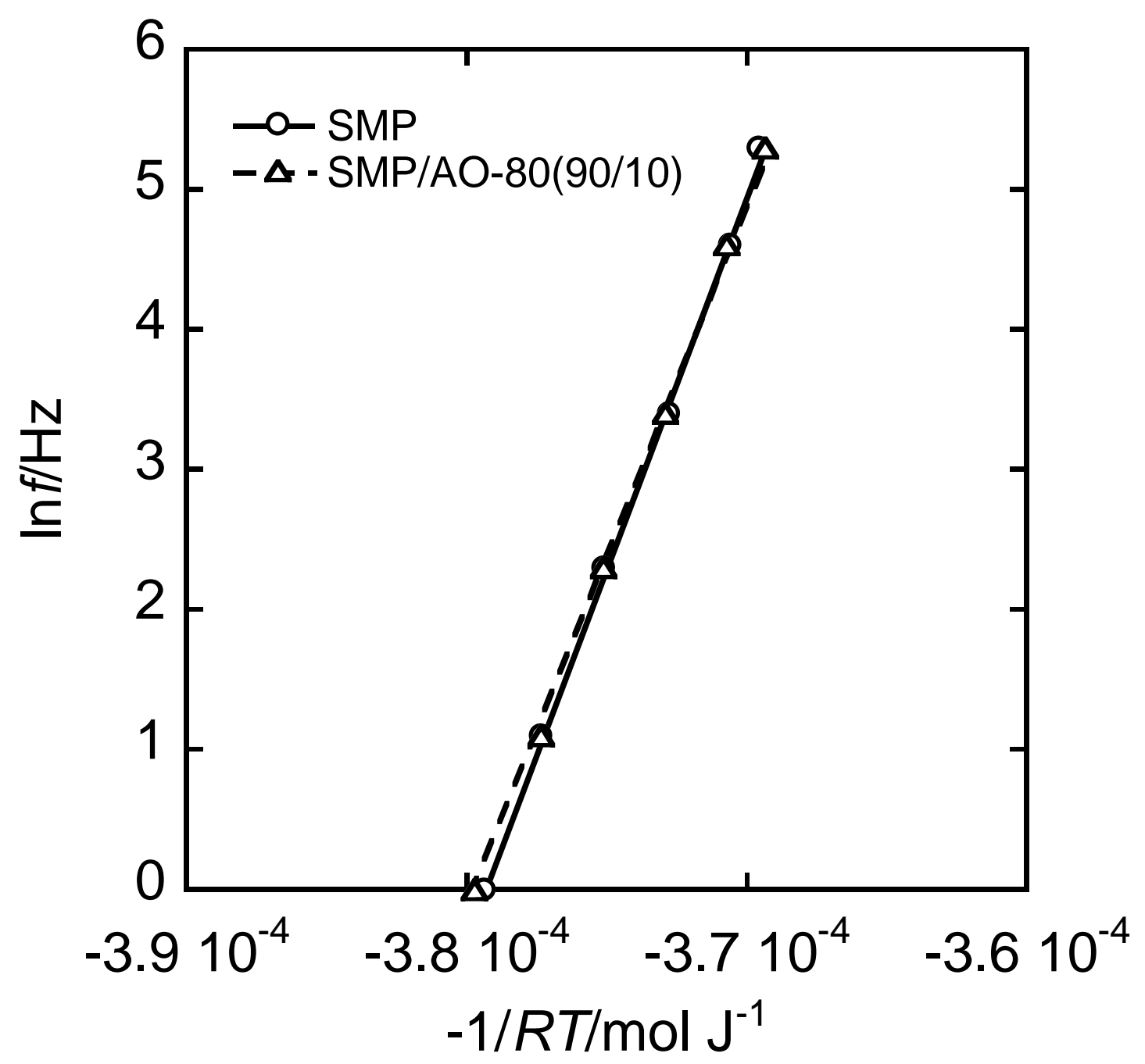

Figure 2 Kuriyagawa 


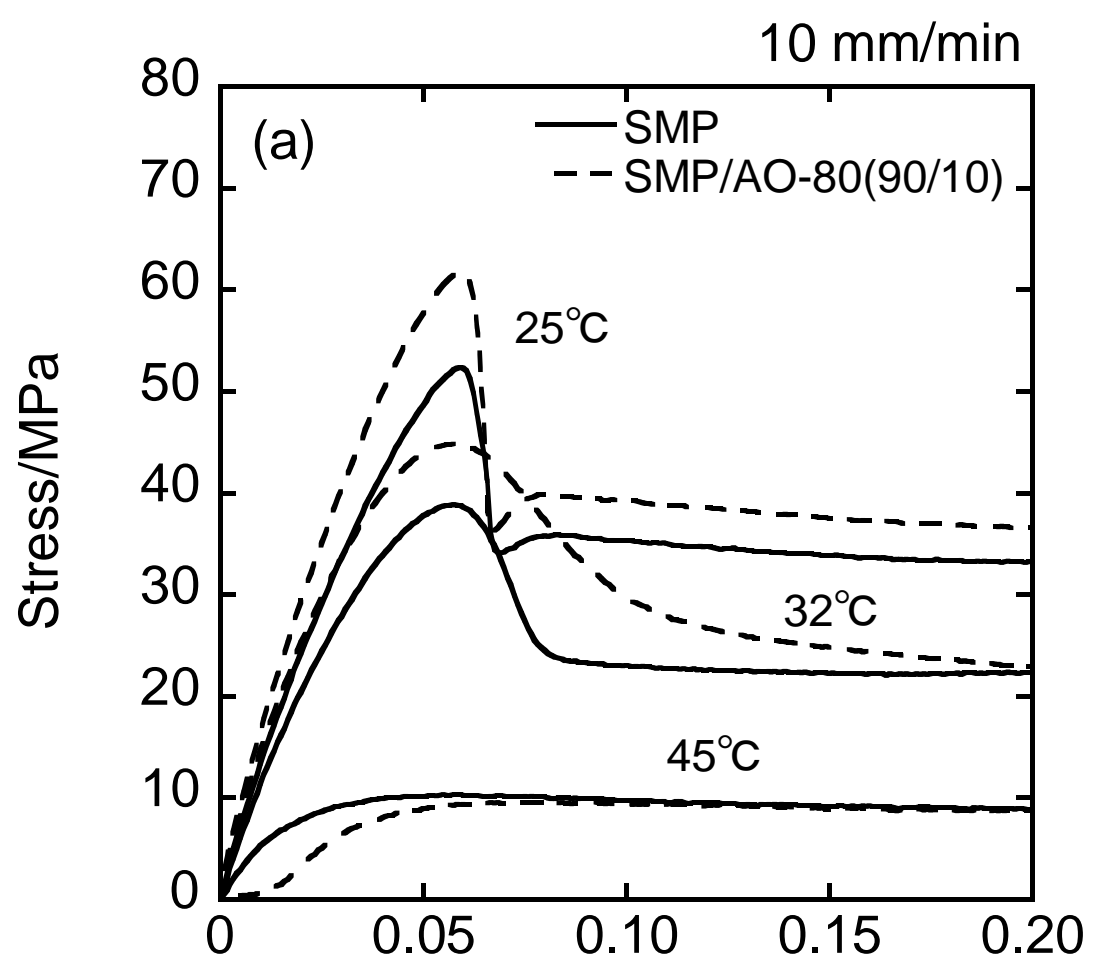

Strain

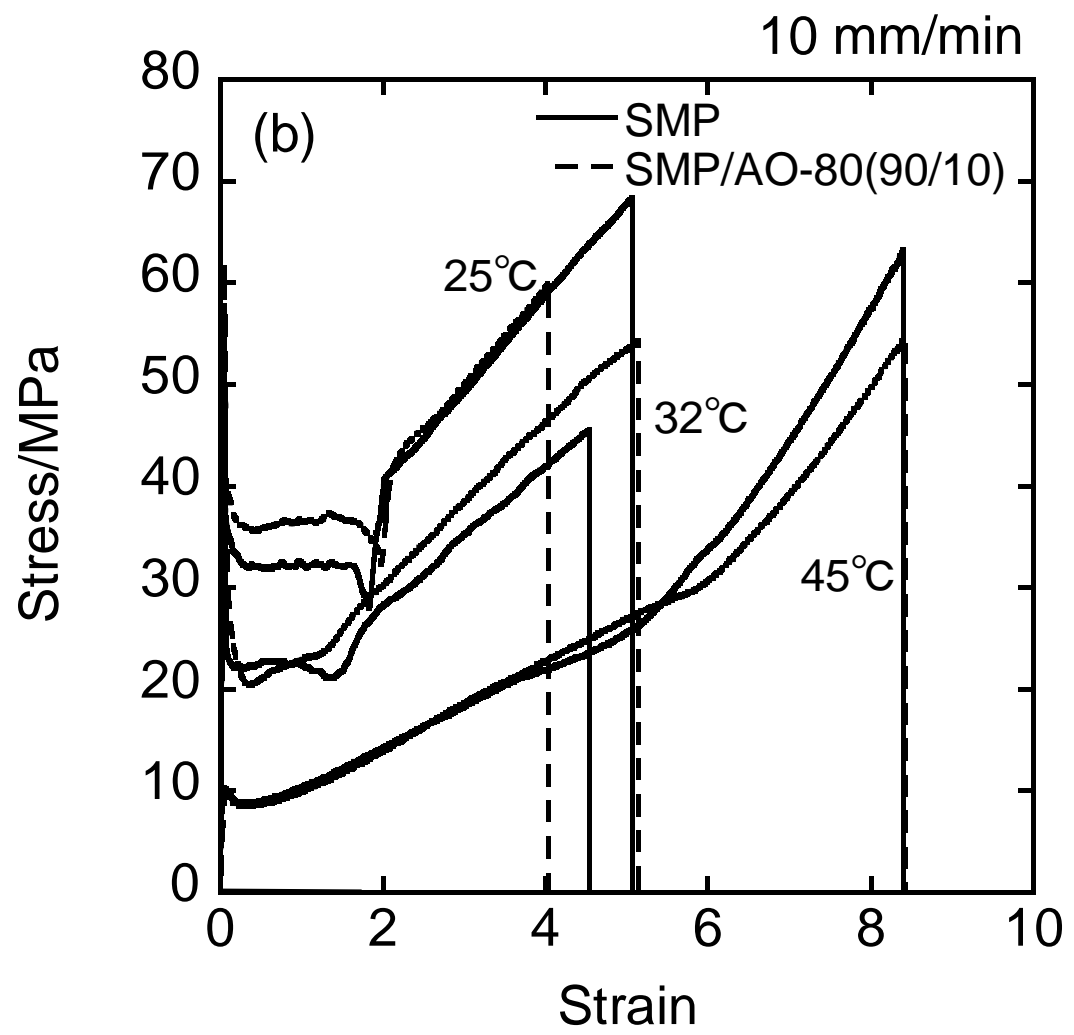

Figure 3 Kuriyagawa 


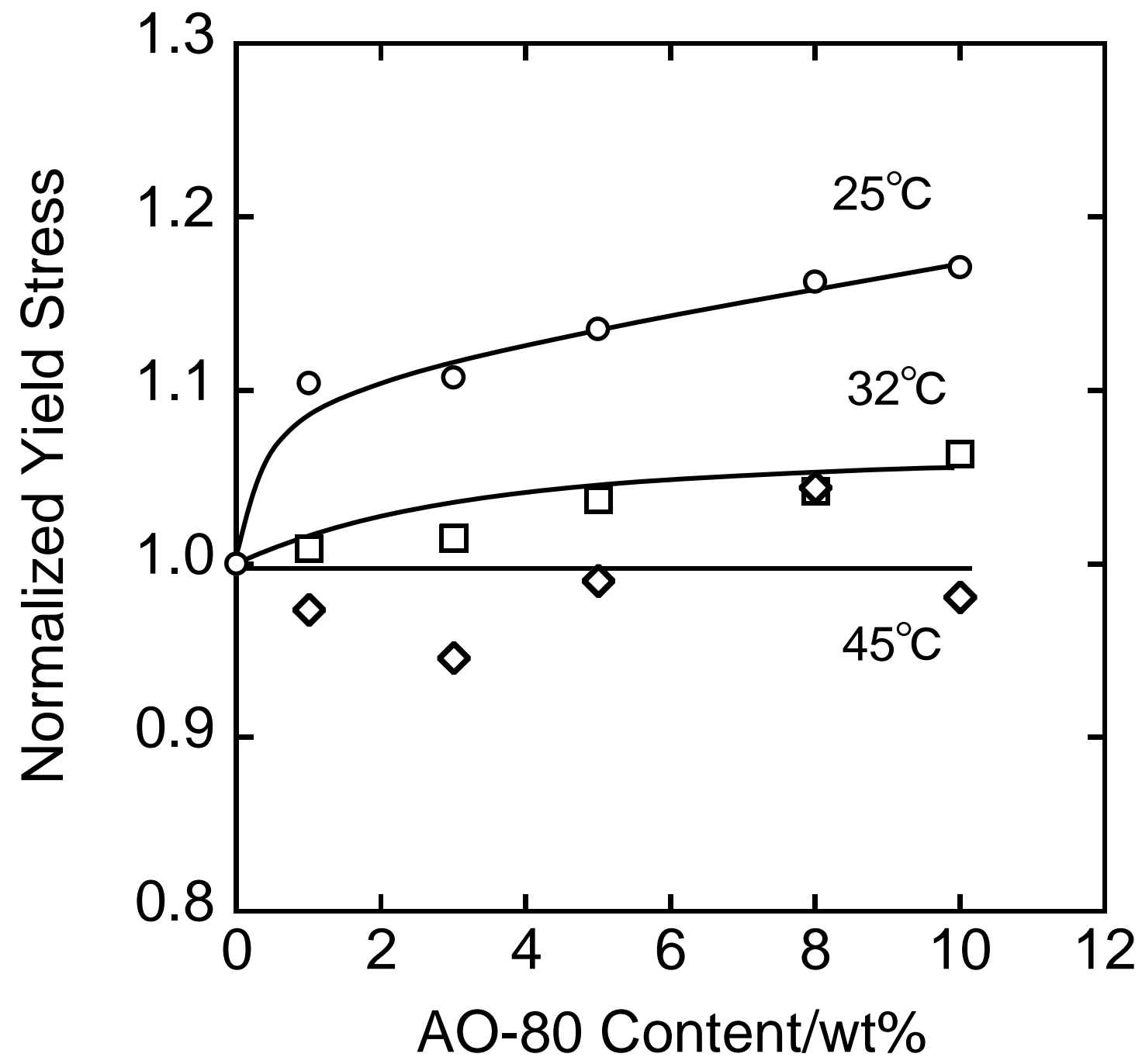

Figure 4 Kuriyagawa 


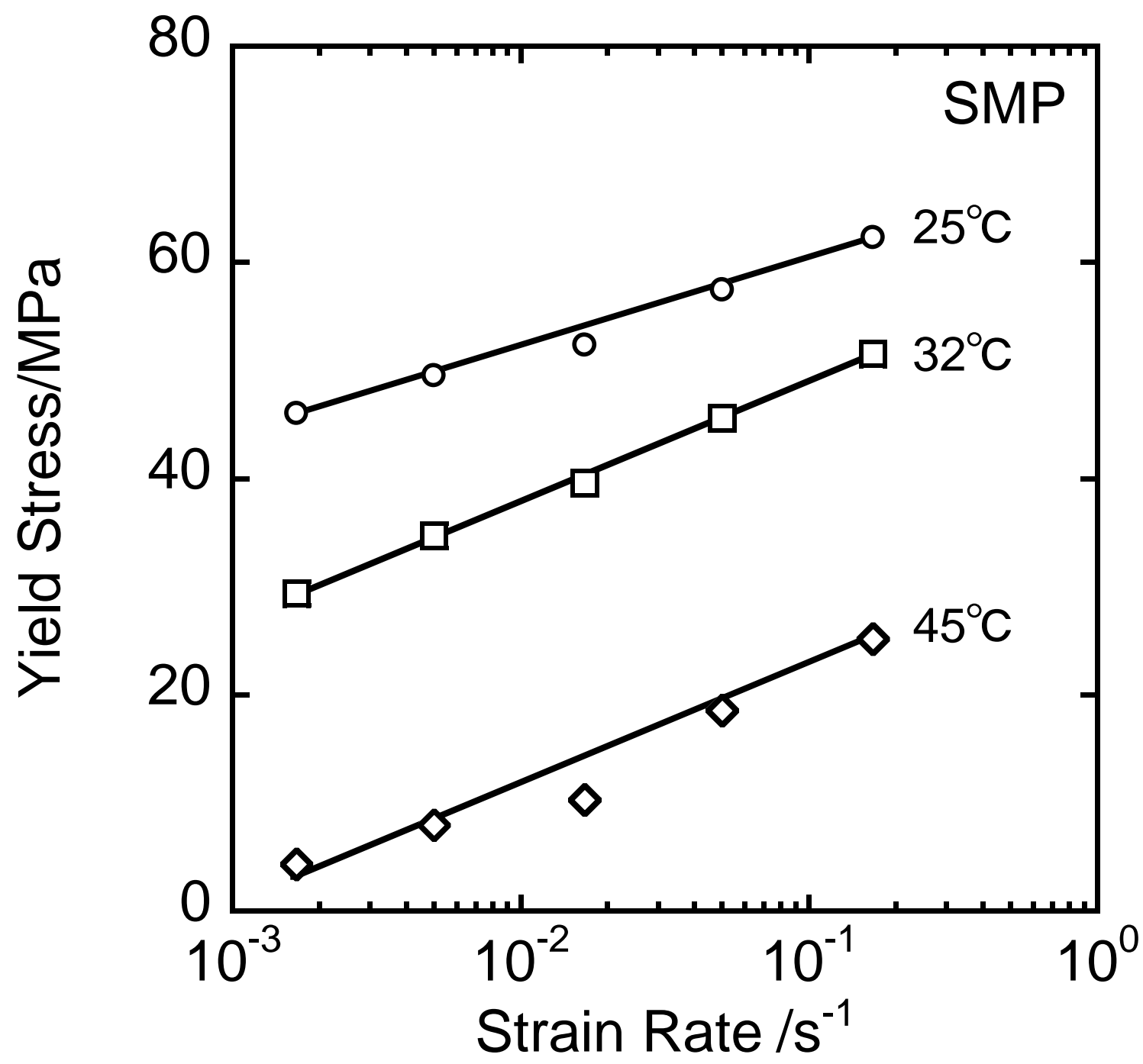

Figure 5 Kuriyagawa 


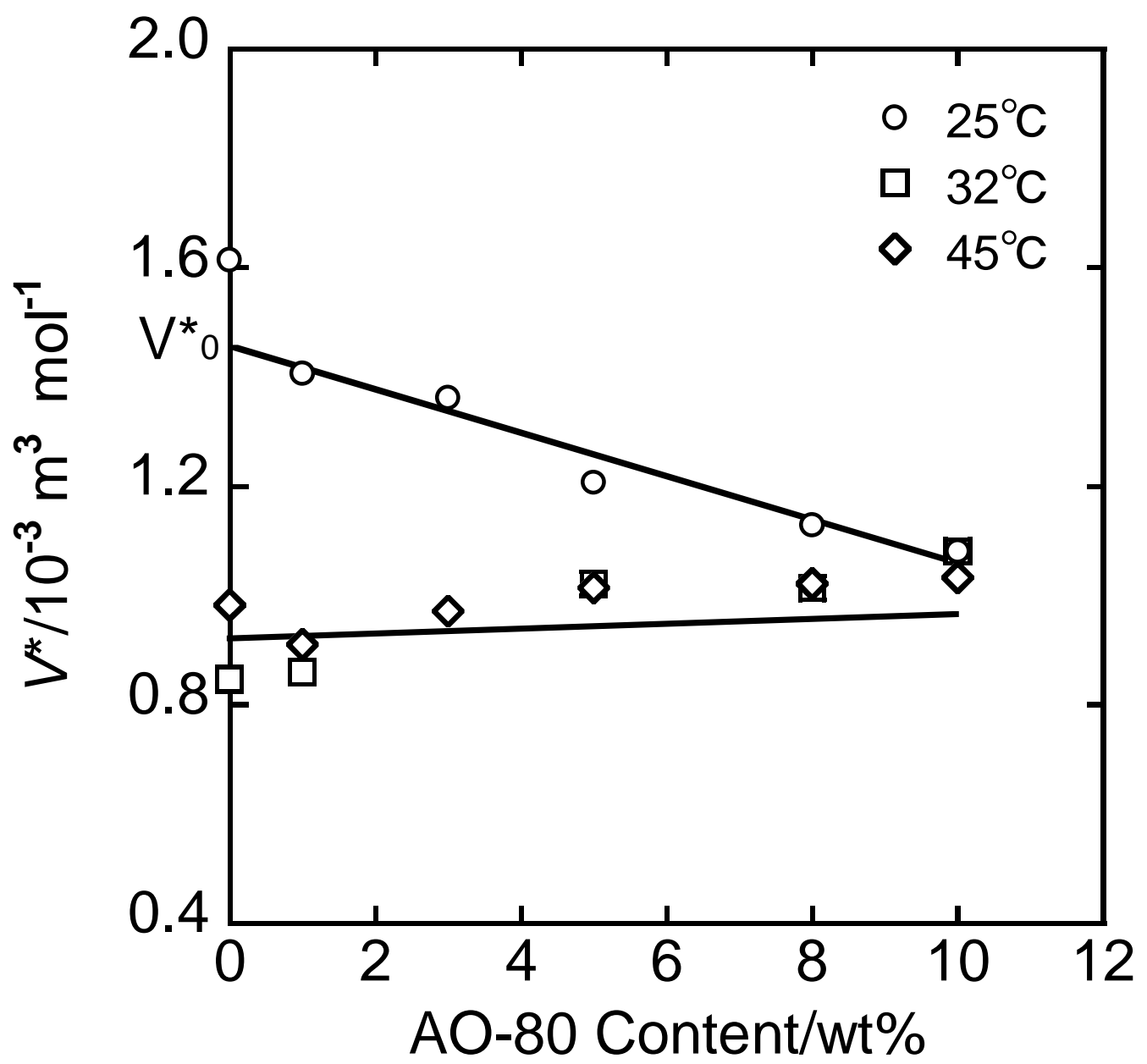

Figure 6 Kuriyagawa 


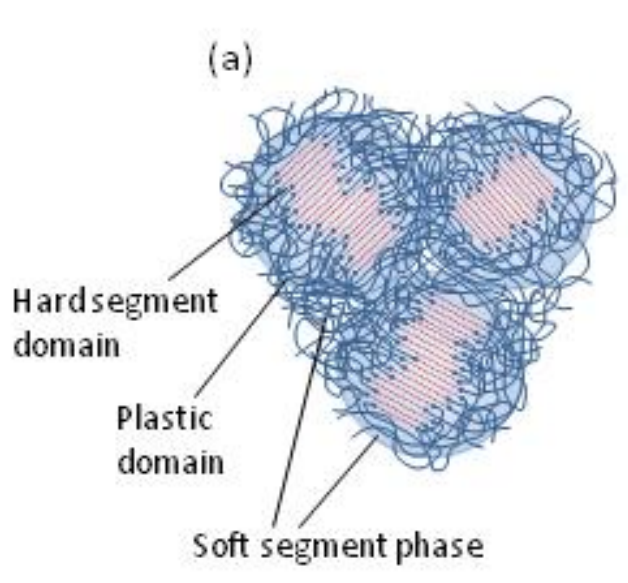

Undeformation

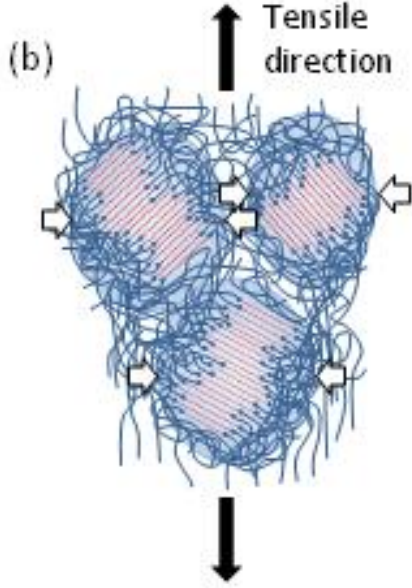

Initial deformation

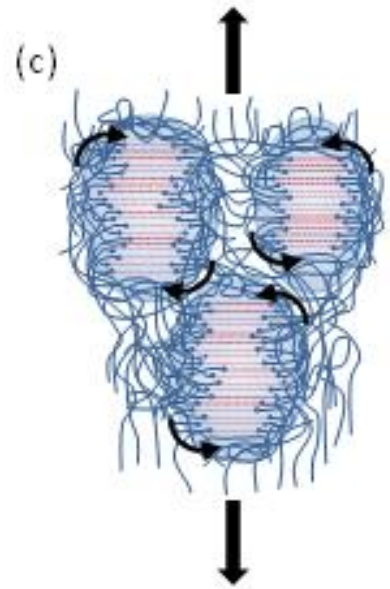

Deformation in the yield region

Fig. 7 Kuriyagawa 
(a)

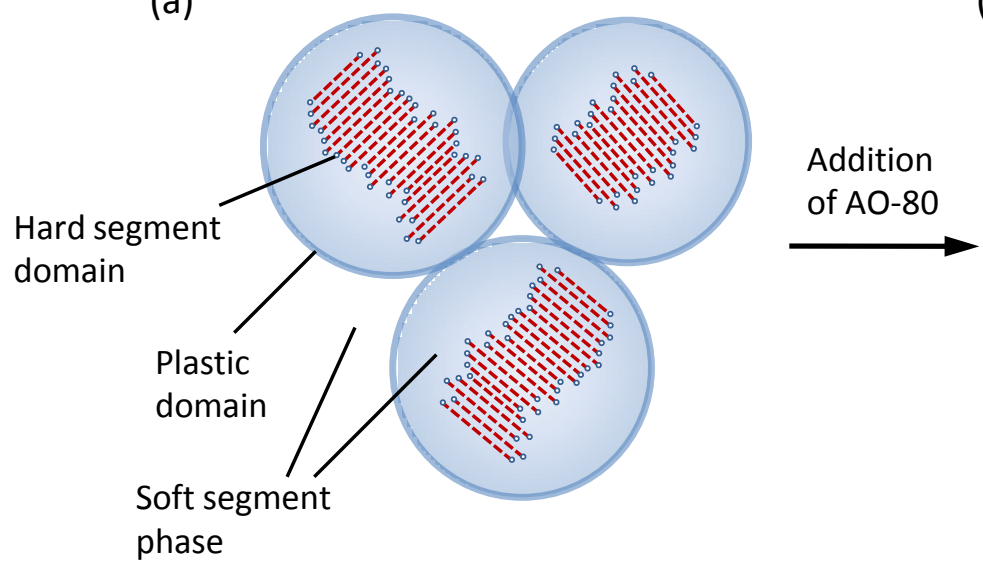

(b)

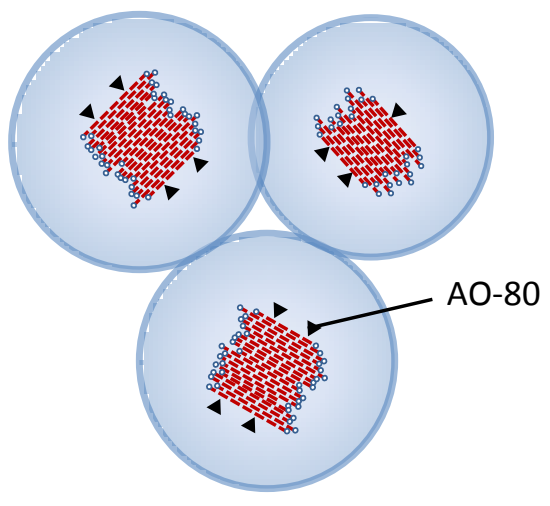

Fig. 8 Kuriyagawa 


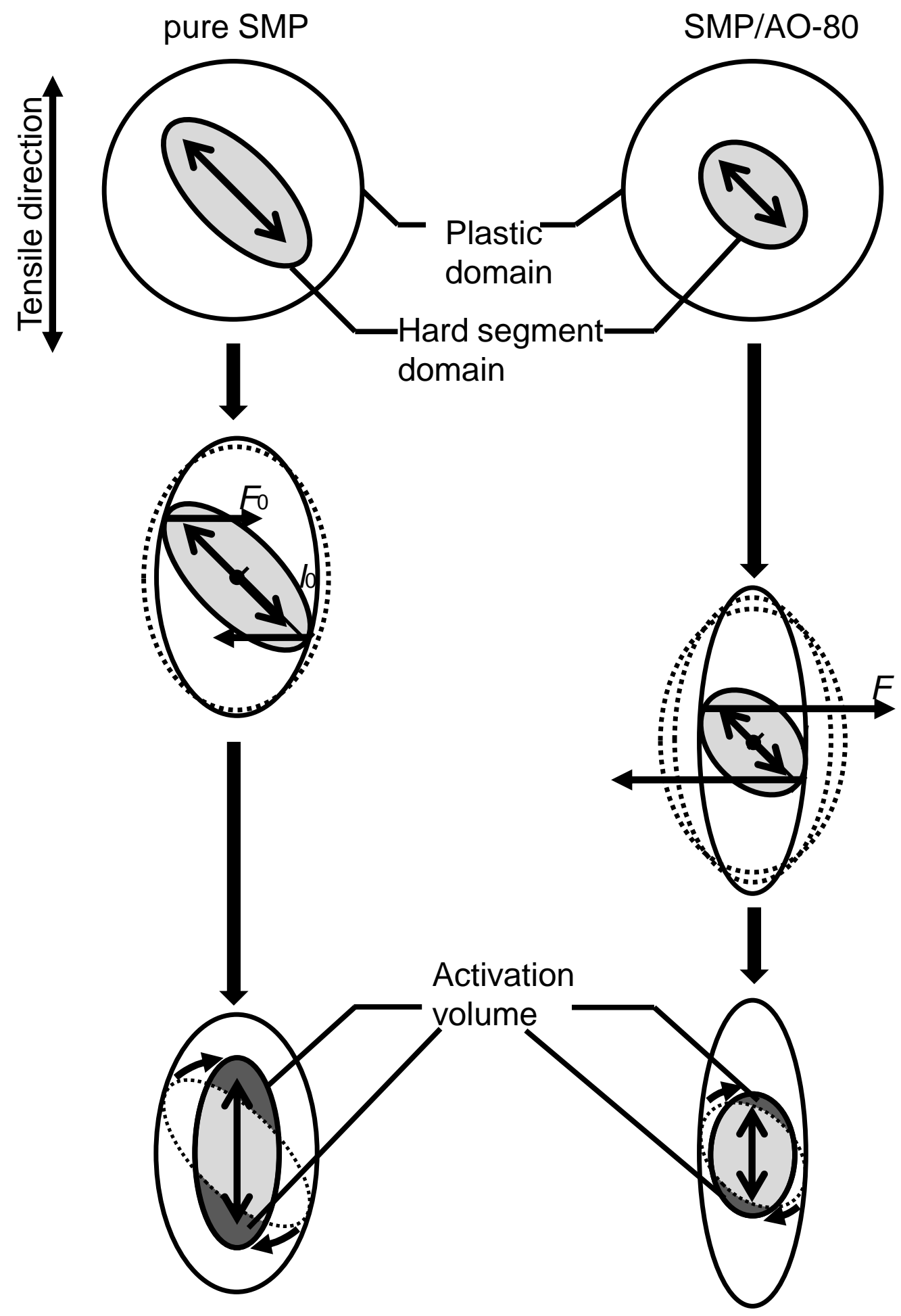

Fig. 9 Kuriyagawa 


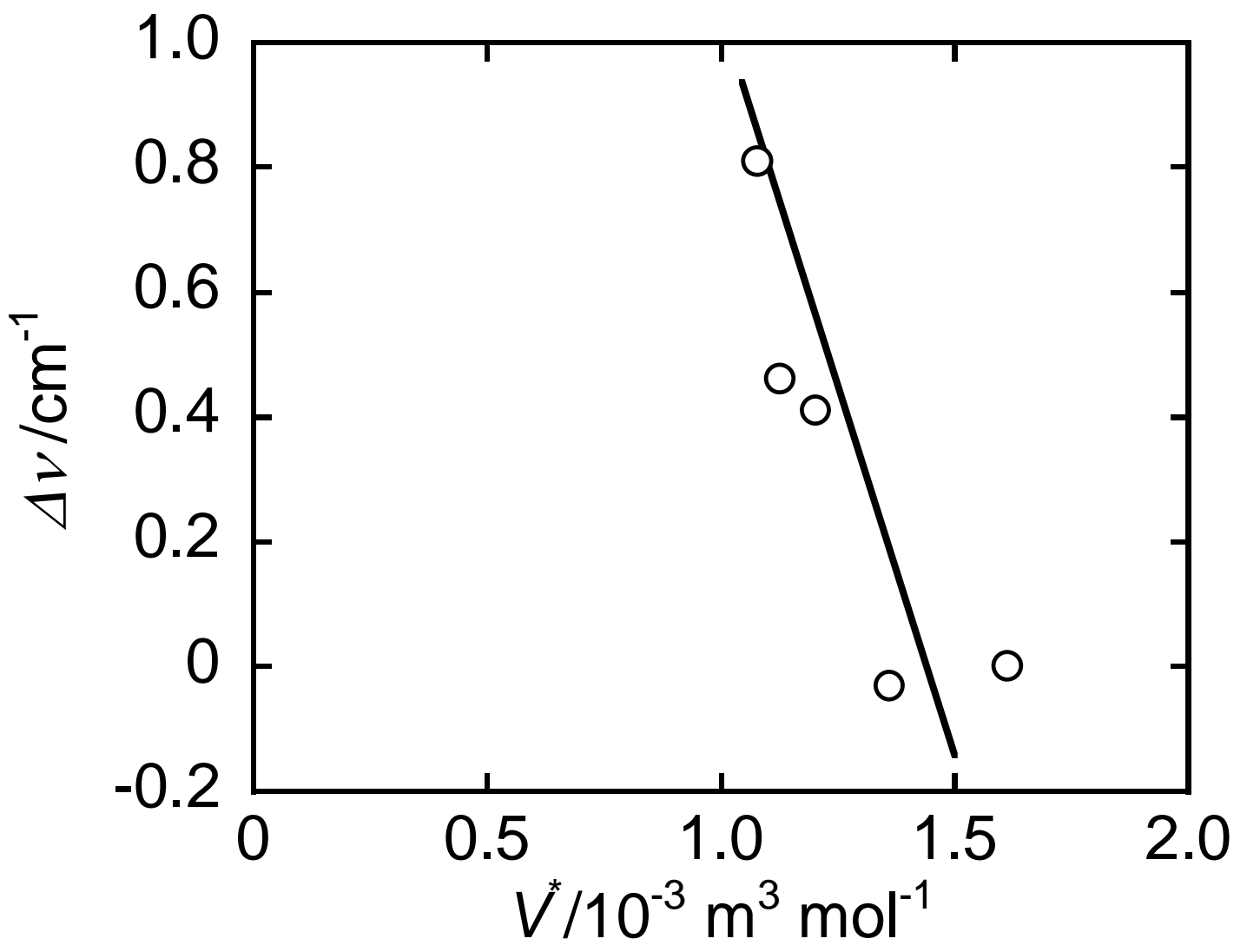

Figure 10 Kuriyagawa 


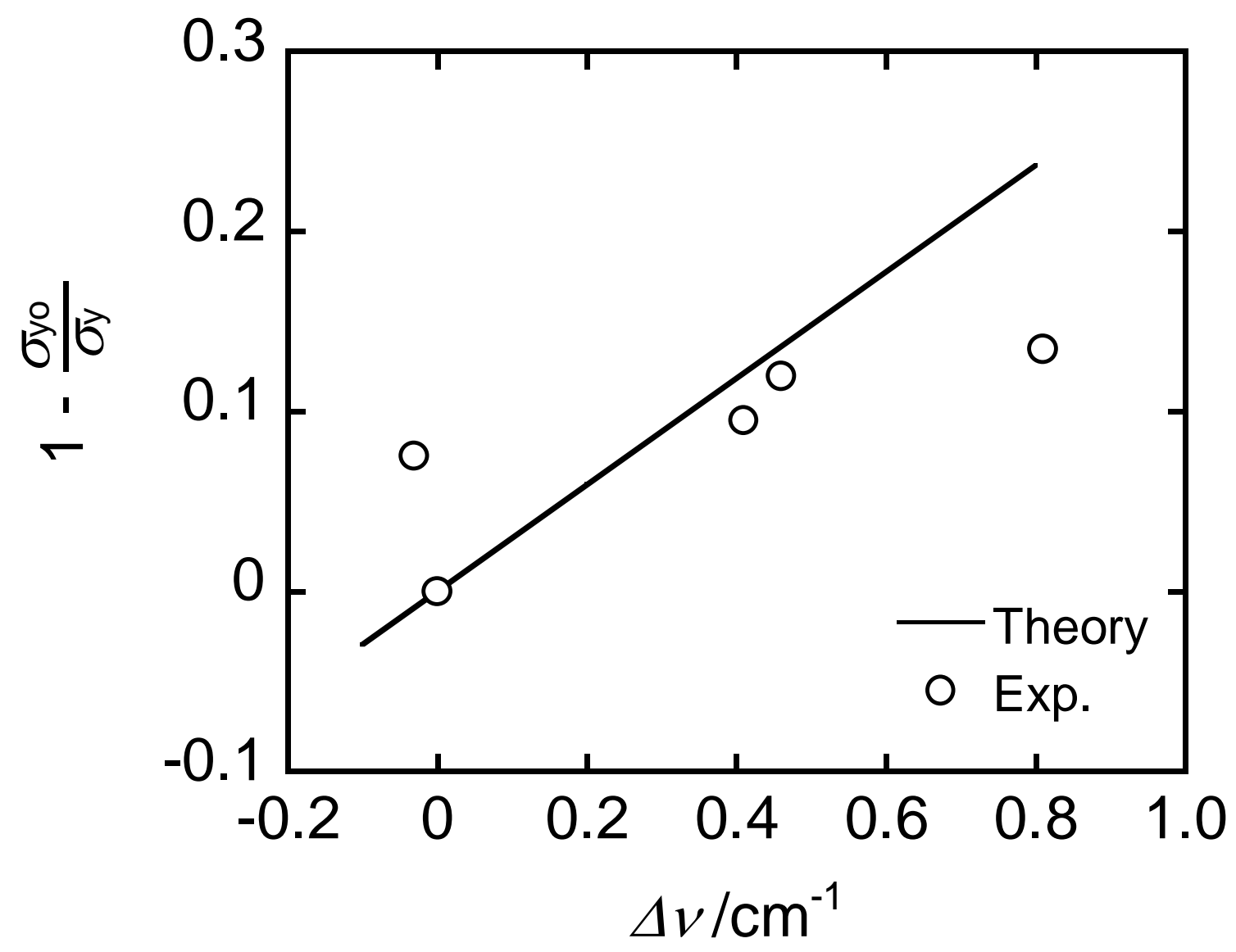

Figure 11 Kuriyagawa 